\title{
Assessment and initial management of feverish illness in children younger than 5 years: summary of NICE guidance
}

Clarification-This NICE guideline summary (BMJ

2007;334:1163, doi:10.1136/bmj.39218.495255.AE) has now been superseded by a summary of updated guidance at www. bmj.com/content/346/bmj.f2866.
Cite this as: BMJ 2013;346:f3764

(๑) BMJ Publishing Group Ltd 2013 